\title{
Hydrologic Modeling for Sedimentation in Hemrin Reservoir Using HEC-HMS
}

\author{
Thair H. Abdullah, Qassem H. Jalut, Yousif W. Ameen \\ Department of Civil Engineering, College of Engineering, University of Diyala \\ qjalut@gmail.com, you93sif@gmail.com
}

\begin{abstract}
Hemrin dam is an important dam in Iraq located on Diyala river which is considered as main tributary of Tigris. The sedimentation is very difficult problem and is considered the major problem affecting the utilization of the dam. HEC-HMS 4.1 software was used to made a simulation for sedimentation in Hemrin reservoir in order to estimate the amount of sediment entering and deposition in the reservoir for the period (1981-2014). The calibration processes were performed using field measurement data for flow of water from Diyala river, the result obtained from simulation process found that the average annual sediment discharge load to Hemrin reservoir is $\left(3.43 \times 10^{6}\right.$ Ton), while the average annual sediment deposited is $\left(3.25 \times 10^{6}\right.$ Ton $)$.
\end{abstract}

Keywords: Hemrin reservoir, HEC-HMS, Sedimentation, Diyala river

Paper History: (Received: 6/3/2017; Accepted: 2/8/2017)

\section{Introduction}

Most natural river arrived almost balanced with respect of sediment inflow and out flow, the construction of dam dramatically change this balance, make an impounded in river has low flow velocities and has high efficiency for sediment trapping, the sediment trapped will reduce the storage capacity of the reservoir, this problem consider the main problem that effect on the useful life of the reservoir, the sediment will deposited in the bed of reservoir in the longitudinal direction with three zones and the position of settling for particle is largely effected by its size, we cannot prevent the sedimentation in reservoir but we can do a sediment management to decreasing the harmful effects of sedimentation, this processes done by basic sediment control strategies such as reducing sedimentation inflow by using technique to control on erosion and sediment removal by flushing or dray excavation[1]. Sedimentation lead to loss in storage capacity of reservoir around the world this is show in Table 1.

There are many studies concerning on reservoir sedimentation decades ago such as.
Brune 1953 formulated the relationship between the capacity-inflow ratio of the reservoir and the trap efficiency[2]. Cristofano 1953 developed method called (Areaincrement method ) for predict the distribution of sediment in reservoir[3]. Yucel and Graf 1973present a mathematical model for calculation the volume of sediment deposited in the reservoir, the model was tested on hypothetical reservoir and use three different model (scotklitch equation, the meyer-peter and Einsten bed load equation) and made compression between the result obtained from these equation[4]. Lopez 1978 developed a mathematical model to estimate the amount and pattern of sedimentation in reservoir, the model based on jet theory, the result show a good agreement between the model result and observed data in Colorado river[5]. Mohammed. et.al 2016 made the compression between the results of sediment transport obtain from WEEP model and SWAT model with observed data for Dhouk dam reservoir, the compression prove that the tow model have a reasonable agreement with observed data[6].This research is aims to maid a simulation for sedimentation in hemrin reservoir.

Table 1 worldwide storage losses due to sedimentation [9].

\begin{tabular}{|c|c|c|}
\hline Region & Storage $\mathrm{km}^{3}$ & $\begin{array}{c}\text { Annual loss due to sedimentation } \\
\text { (\% residual storage ) }\end{array}$ \\
\hline World wide & 6325 & $0.5-1$ \\
\hline Europe & 1083 & $0.17-0.2$ \\
\hline North America & 1845 & 0.2 \\
\hline $\begin{array}{c}\text { South and Central } \\
\text { America }\end{array}$ & 1039 & 0.1 \\
\hline North Africa & 188 & $0.08-1.5$ \\
\hline Sub Saharan Africa & 575 & 0.23 \\
\hline Middle East & 224 & 1.5 \\
\hline Asia (excluding China) & 861 & $0.3-1.0$ \\
\hline China & 510 & 2.3 \\
\hline
\end{tabular}

\section{2- Study Area}

The study area is the watershed of Hemrin dam reservoir. Hemrin dam is an gravel fill dam with clay core, the position of dam is $120 \mathrm{~km}$ northeast of Baghdad on course of Diyala river, the dam was built for multipurpose such as flood control and regulation of water for irrigation, the dam has $40 \mathrm{~m}$ high and $3360 \mathrm{~m}$ length with $170.5 \mathrm{~m}$ (a.s.l) as maximum design 
elevation. The total storage of reservoir is 3760 MCM. The study area include upper Diyala basin and middle Diyala basin which can divided into Subbasin, some properties of these Subbasin are shown in Table 2 , the climate in study area has main role in sediment discharge to the reservoir because it is effect on the amount of annual precipitation which in turn effect on the rate of erosion, the climate in the study area effect by the air from the Mediterranean sea for period from October to March which consider the rain season while from April to September the percentage of precipitation is $25-30 \%$ of the total annual precipitation[7]. The geometric characteristic are shown in Table 2. While Diyala river basin show in Figure 1.

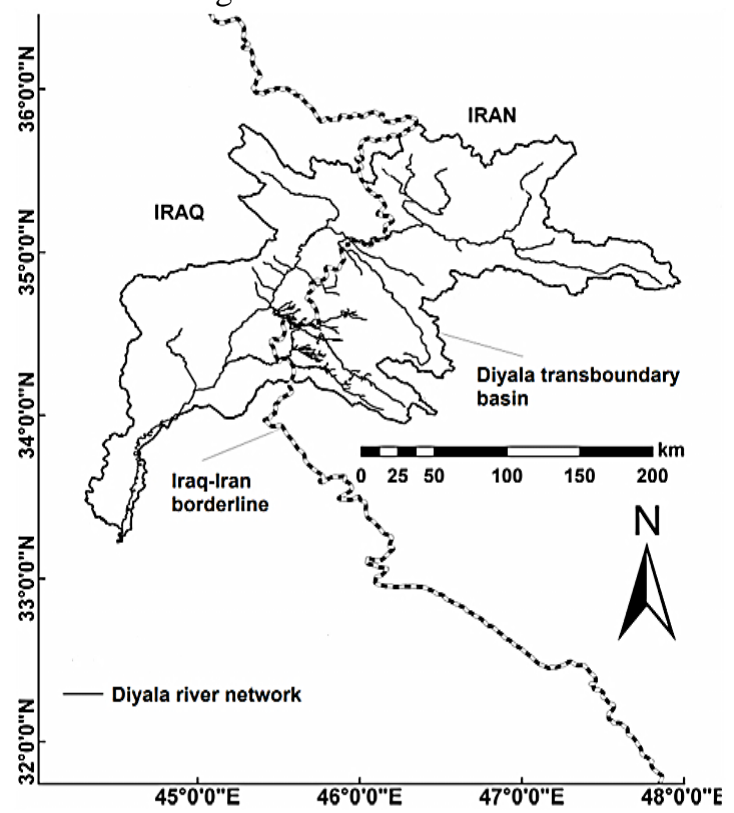

Figure 1: Diyala river basin [11]

\section{Mathematical Simulation}

The hydrologic modeling system (HEC-HMS) is designed to make the simulation of precipitation-runoff in watershed system, the program capable to simulate the erosion and sediment transport in the different element in the watershed including deposition of sediment in the reservoir, to the simulation, the model needs some input data such as the metrological data(daily precipitation) and some geometric properties for each element like the area of Subbasin, the cross section of the reach and the elevation- area relationship of reservoir, the model use some theory to simulate the sediment transport, to the runoff-process the model use ScS unit hydrograph while for erosion from the Subbasin the model use Modified Universal Soil Loss Equation (MUSLE), to calculate sediment load (ton) [8].

$S L=11.8 \cdot\left(Q \cdot q_{\text {peak }}\right)^{0.56} \cdot K \cdot L S . C . P$
SL is sediment yield for a given event (ton ), $\mathrm{Q}$ is the surface runoff volume $\left(\mathrm{m}^{3}\right), \mathrm{q}_{\text {peak }}=$ the peak runoff rate $\left(\mathrm{m}^{3} / \mathrm{s}\right)$, while $\mathrm{K}, \mathrm{LS}$ are the soil erodibility factor and the topographic factor respectively, $\mathrm{C}$ is the cover and management factor and $\mathrm{P}$ is the support practice factor.

Also fall velocity method are required to assist the model in order to simulate the deposition of particle in different element in watershed. The program contain a number of fall velocity method and allows the user to select one of them, in this study vanrijin fall velocity is used:

$\omega=\frac{(s-1) g d}{18 \mathrm{v}} \quad 0.001<\mathrm{d} \leq 0.1 \mathrm{~mm}$

$\omega=\frac{10 \mathrm{v}}{d}\left[\left(1+\frac{0.01\left(s-1 g d^{3}\right.}{\mathrm{v}^{2}}\right)^{0.5}-1\right] 0.1<\mathrm{d}<1 \mathrm{~mm}$

$\omega=1.1[(s-1) g d]^{0.5}, \quad \mathrm{~d} \geq 1 \mathrm{~mm}$

$\omega=$ particle fall velocity, $\mathrm{v}=$ kinematic viscosity, $\mathrm{s}=$ specific gravity and $\mathrm{d}=$ particle diameter.

HEC-HMS exploits Chen sediment trap method to calculate the amount of sediment deposited in the reservoir:

$$
\begin{aligned}
& \mathrm{TE}=100\left[1-e^{-\frac{v_{S}}{v_{c}}}\right]_{S} \\
& \mathrm{TE}=\text { trap efficiency } \\
& v_{s}=\text { settling velocity of sediment particle } \\
& v_{c}=\text { the critical settling velocity }
\end{aligned}
$$

\section{Results and Discussion}

The Hec-Hms model was applied to predict the runoff and sediment load inflow to Hemrin reservoir for the period 1/1/1981- 31/12/2014, the peak discharge obtain from the model was 1471 (cms) in March1988 due to the volume of rainfall was happened at this period, the compression are made between the flow predict by the model and the actual flow shown in Figure 3, and this compression reveals a reasonable agreement between model and actual data( $\left.\mathrm{R}^{2}=0.7805\right)$. After calibrated the model, the sediment simulation is run and this sediment load in Figure 4, the sediment inflow to Hemrin reservoir is strongly related to water flow, while in Figure 5 the annual sediment inflow to Hemrin reservoir is represented and demonstrated that the peak annual sediment is 
in 1998 consistent with the peak annual water flow, Figure 6 show the sediment load deposited in Hemrin reservoir. the result show that Hemrin reservoir lost about $164 \mathrm{MCM}$

from its storage capacity

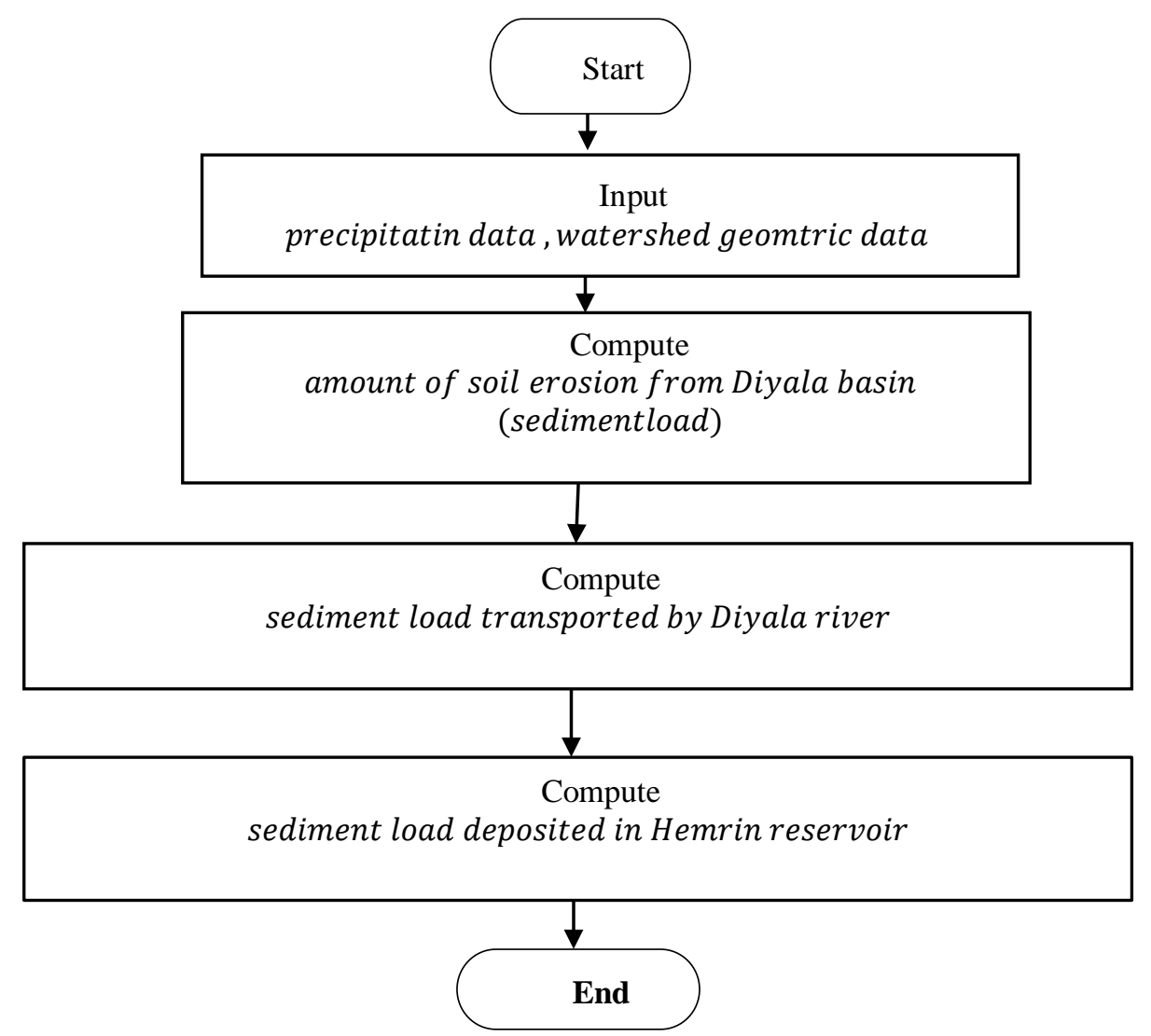

Figure 2 : General simulation flow chart 


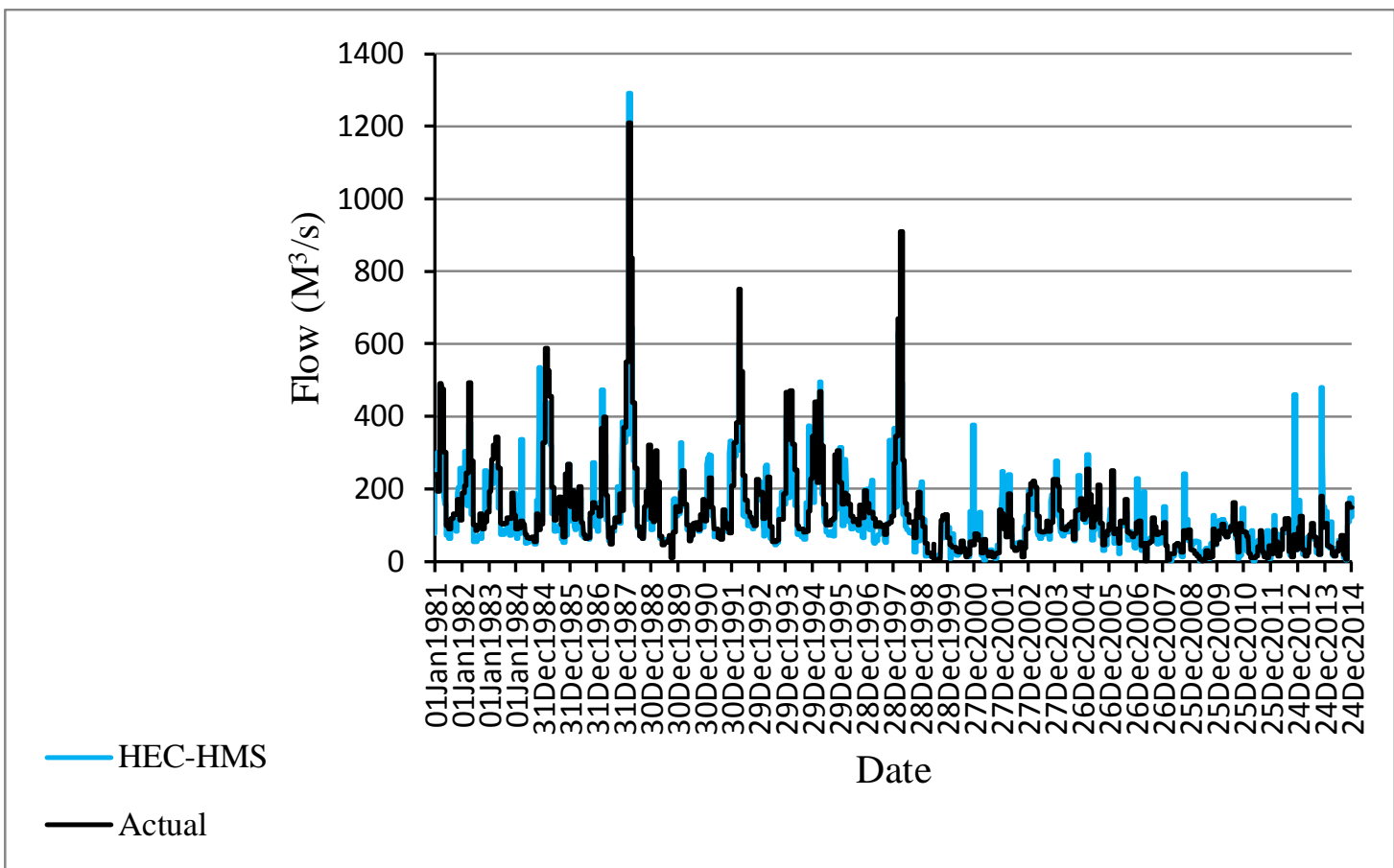

Figure 3 . Water inflow for hemrin reservoir

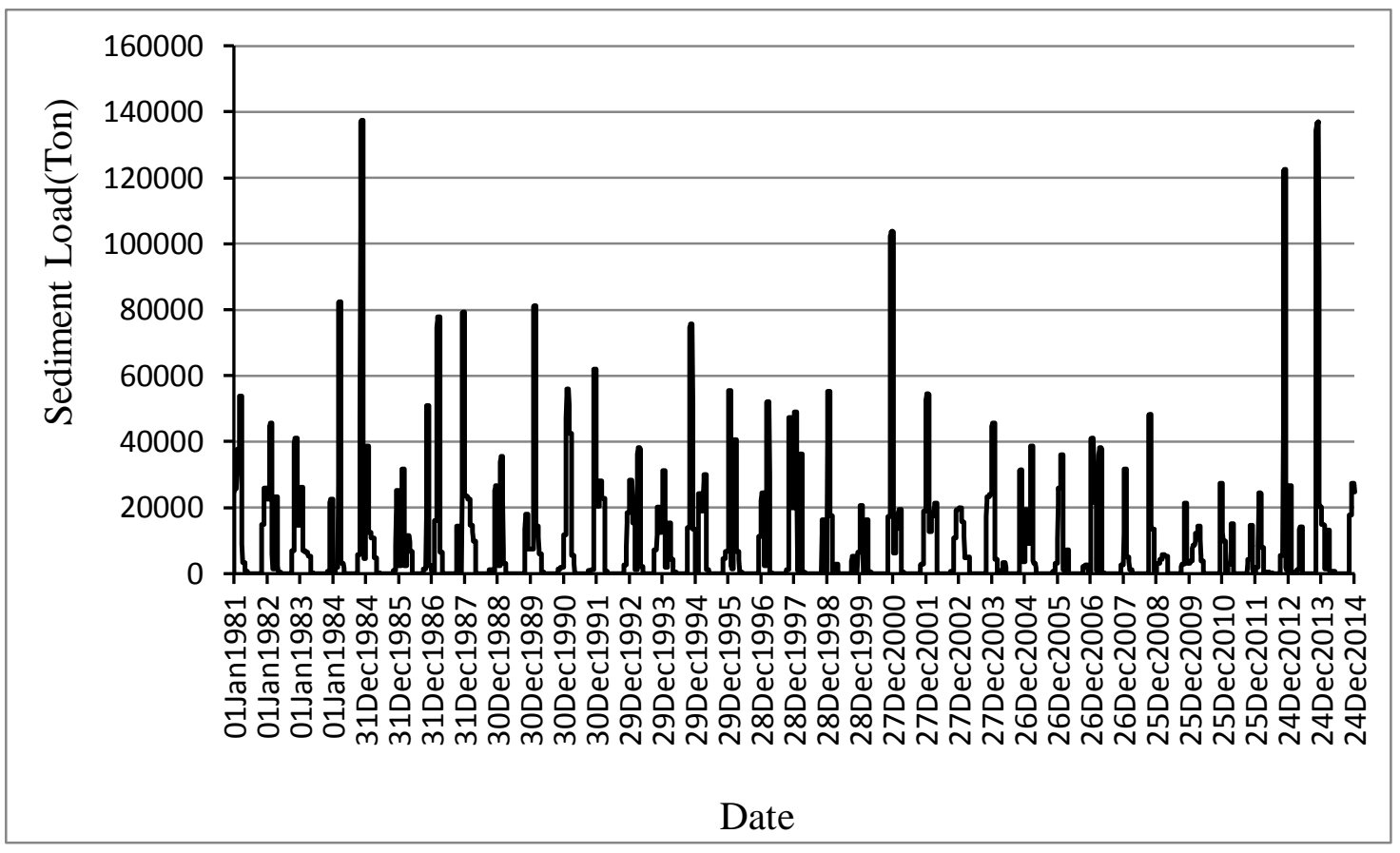

Figure 4. Sediment inflow to Hemrin reservoir 


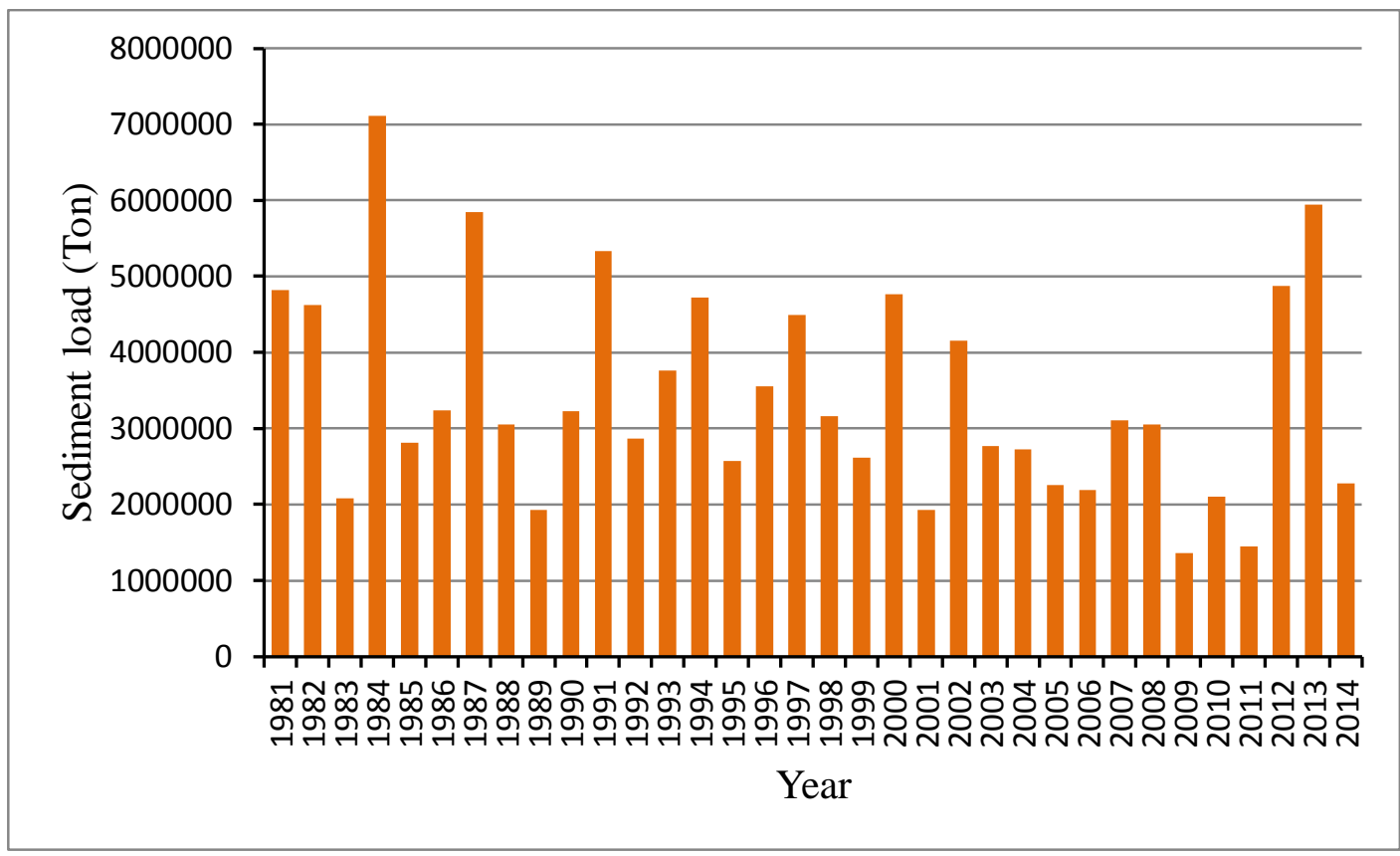

Figure 5. Annual sediment discharge to hemrin reservoir

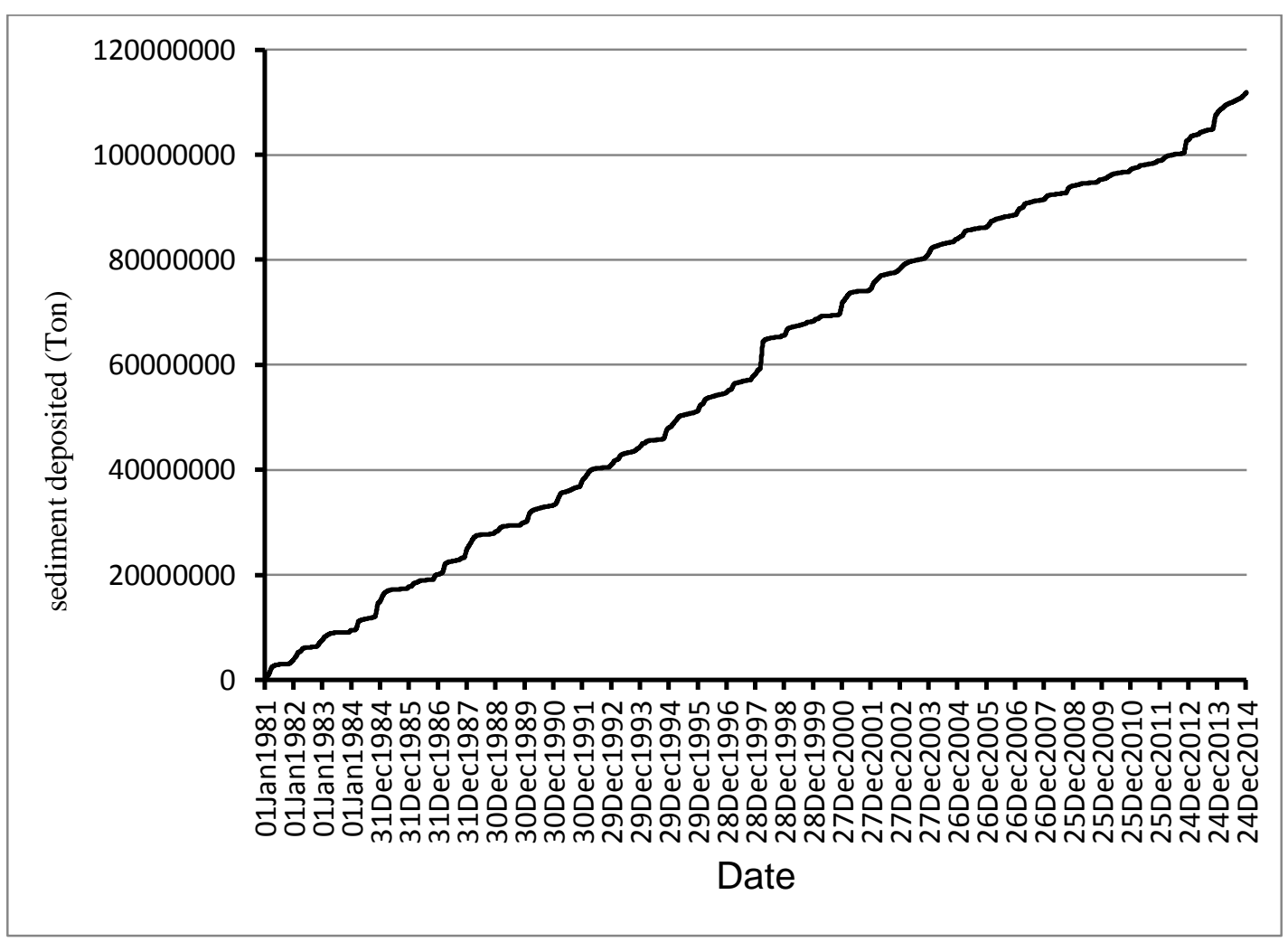

Figure 6 . The amount of sediment deposited in Hemrin reservoir

\section{Conclusions}

1- The load of sediment entering Hemrin reservoir is directly affected by the precipitation depth in Diyala river basin so the largest value of sediment income to reservoir occurred in November due to the largest value of precipitation which occurred at that time.

2- The deposited sediment volume in reservoir greatly affected by the load of sediment coming to the reservoir (94\% of sediment entering to the reservoir will be deposit) 
3- the average annual sediment discharge was $\left(3.43 \times 10^{6}\right.$ ton $)$, while the average annual sediment deposited in reservoir was $\left(3.25 \times 10^{6}\right.$ ton).

\section{References}

[1]. Morris, G. L. \& Fan, J., Reservoir Sedimentation Handbook. 1.04 ed. New York: McGraw-Hill Book, 2010.

[2]. Brune, G. M., Trap efficiency of reservoirs. Eos, Transactions American Geophysical Union, 34(3), (1953), 407-418.

[3]. Cristofano, E.A., Area Increment Method For Distributing Sediment in Reservoir. US. Bureau of Reclamation, Al buquerque, NEW MEXICO, 1953.

[4]. Yucel, O., \& Graf, W. H., Bed Load Deposition and Delta Formation: A Mathematical Model. Lehigh University, Fritz Engineering Laboratory, 1973.

[5]. Lopez, j. L, (1978). Mathematical Modeling of sediment Deposition in Reservoir. Hydrology paper, Colorado state University, (1978), 95.

[6]. Mohammed, M.E, AL-Ansari, N. and Knutsson, S., Annual Runoff and Sediment in Duhok Reservoir watershed Using SWAT and WEEP models. Engineering, 8, (2016), 410422.

[7]. Al - Ansari , N. A.. Geological and Hydrological investigation of Hemrin reservoir, J .of water resources, special publication, (1987), 2.

[8]. Arnold, J.G., Srinivasan, R., Muttiah, R. and. Williams, J., Large Area Hydrologic Modeling and Assessment Part I: Model Development. Journal of American Water Resources Association,34, (1998), 73-89.

[9]. Palmieri, A., Shah, F., Annandale, G., \& Dinar, A., Reservoir conservation volume I: the RESCON approach. Washington, DC: World Bank., 2003.

[10]. AL-Jubouri.T.A., Hydrology and Geomorphology Of Diyala Basin. Unpublished Doctoral dissertation, University of Baghdad, Baghdad, Iraq. (Arabic print. 1991.

[11]. AL- Faraj .Furat .A.M, Miklas Scholz and Dimitiris Tigkas. Sensitivity of Surface Runoff to Drought and Climate Change : Application for Shared River Basins. Water,6, (2014), 3033-3048. 